\title{
UM ESTUDO TEOLÓGICO DAS DIRETRIZES PASTORAIS DA CONFERÊNCIA NACIONAL DOS BISPOS DO BRASIL (CNBB) $(1991-2002)^{1}$
}

Me. Pedro Donizeti de Campos*

\section{RESUMO}

O presente artigo procura demonstrar que a mudança ocorrida na formulação e na apresentação das Diretrizes Gerais, não mais como "Ação Pastoral" e sim "Ação Evangelizadora", não foi apenas uma mudança de nomenclatura, mas a gênese de uma evolução eclesiológica. Inicia-se assim uma "revolução copernicana" no que tange à compreensão e ao lugar que a Evangelização deve ocupar na ação da Igreja do Brasil. Ela passa de uma mera Dimensão da Pastoral para se tornar a razão de ser e de agir de toda ação pastoral da lgreja.

Palavras-chave: Igreja no Brasil. Evangelização. Pastoral.

\section{ABSTRAT}

This article shows that the change in the formulation and presentation of the General Guidelines, not, any longer, as "Pastoral Action" but "Evangelizing Action", was not only a change in nomenclature, but the genesis of an ecclesiological evolution. In this context begins a "Copernican revolution" in what refers to the understanding and the place the Evangelization should occupy in the way that the Church in Brazil proceeds. It changes from a mere Pastoral Dimension to become the reason for being and proceeding of all pastoral activity of the Church.

Keywords: Church in Brazil, Evangelism, Pastoral.

1 O presente artigo é uma segunda apresentação a partir de minha dissertação para obtenção do título de Mestre em Teologia Dogmática apresentada na Pontifícia Faculdade de Teologia Nossa Senhora da Assunção e defendida no dia 29 de junho de 2006 sob a orientação do Professor Dr. Ney de Souza.

* Sou Padre Missionário ordenado a quase 10 anos, membro de uma Associação Pública de Fiéis, cognominada "Comunidade Missionária Providência Santíssima", fundada em Jardinópolis e atualmente residente em Mococa. Hoje moro e exerço meu ministério sacerdotal na França, na Diocese de Fréjus-Toulon, no VAR.Paulo. Exerce seu Ministério Presbiteral na Capela do Colégio Sion. E-mail: juleva@pucsp.br 


\section{INTRODUÇÃO}

O presente artigo propõe-se a analisar, de forma teológica, a evolução eclesiológica da Igreja no Brasil, a partir de suas Diretrizes Gerais. Serão objeto de nosso estudo as Diretrizes Gerais referentes ao espaço de tempo entre 1991 a 2002. Sendo assim, por razões metodológicas, nos ateremos apenas na analise teológica das duas Diretrizes em questão, ou seja, as "Diretrizes Gerais da Ação Pastoral da Igreja no Brasil -1991-1994 - (DGAP, n. 45)"1 e as "Diretrizes Gerais da Ação Evangelizadora da Igreja no Brasil -1995-1998 - (DGAP, n. 54)".

Sensível aos "sinais dos tempos", a Igreja no Brasil compreende que, fundamentalmente, necessita mudar não só sua forma de ação pastoral, mas também sua estrutura e, principalmente, a compreensão de sua identidade e de sua missão. É neste período que nossos Bispos promulgam o documento 54, no qual mudam não só o título das Diretrizes, de ação pastoral para ação evangelizadora - mas também a sua estrutura, e consequentemente, muito embora não perceptivelmente, o rosto, o horizonte e a prática pastoral de toda a Igreja no Brasil.

A evangelização passa de uma dimensão da ação pastoral a ser o principio constitutivo de toda ação pastoral. A Evangelização deve ser inculturada e acompanhada de quatro exigências irrenunciáveis expressas pelo serviço, o diálogo, o anúncio e o testemunho de comunhão eclesial. Essas quatro exigências estão em consonância com as seis dimensões. A diferença está no lugar proeminente e de destaque que a missão ocupa.

A partir dessa exposição, é possível perceber a evolução eclesiológica e o novo perfil eclesiológico que se forja a partir das Diretrizes da ação evangelizadora. Uma Igreja mais evangelizadora que pastoral, muito embora não a elimine. Uma Igreja verdadeiramente ministerial, em que todos são sujeitos dessa ação evangelizadora. Uma Igreja que evangeliza e que precisa ser constantemente evangelizada.

Daqui em diante, mencionaremos por razões práticas como Doc. 45.

2 Daqui em diante, mencionaremos por razões práticas como Doc. 54. 


\section{AS DIRETRIZES GERAIS DA AÇÃO PASTORAL E DA AÇÃO EVANGELIZADORA: UMA ANÁLISE TEOLÓGICA}

\subsection{Uma análise teológica do Documento 45}

O Documento $45^{3}$ é depositário de uma longa caminhada pastoral e teológica no que tange principalmente à compreensão da missão como evangelização, oriunda de várias fontes, entre as quais, o Concílio Vaticano II, as Conferencias de Medellín e de Puebla, sem esquecer é claro da influencia eminente do Papa Paulo VI com a encíclica Evangelii Nuntiandi ${ }^{4}$ (EN) e do Papa João Paulo II com a encíclica Redemptoris Missio ${ }^{5}$ (RMi) e, é claro, de toda a realidade conjuntural em que a Igreja no Brasil estava emergida neste período.

Percebe-se no documento 45 uma profunda preocupação e, ao mesmo tempo, uma profunda reflexão sobre o tema da evangelização como fio condutor de toda a vida eclesial. Torna-se claro esta tendência pela não proposta de destaques pastorais, como de costume, em quase todas as outras Diretrizes anteriores. Há, por decorrência de toda a reflexão anterior, um despertar da Igreja para a sua identidade e missão. ${ }^{6}$

Até aqui, todas as Diretrizes, inclusive as expressas pelo documento 45, falam sobre a evangelização a partir da estrutura pastoral baseada nas seis Dimensões ou Linhas. Estas constituem o "quadro referencial da Ação Pastoral, sem esgotar o mistério da Igreja" e "têm a função de mostrar ao mesmo tempo a variedade de aspectos e a unidade dinâmica que deve existir entre eles. De fato, elas se interpenetram e se exigem mutuamente". Embora se fale de interdependência, a missão é nessas Diretrizes assim como nas anteriores, entendida na prática pastoral como um momento da pastoral que não influência as demais. A Linha dois, denominada Linha ou

3 Lembremos que a CNBB, pelo seu organismo de Pastoral o Instituto Nacional de Pastoral (INP), já publicara desde o ano de 1975, outras quatro Diretrizes, ou seja, os Documentos 4-15-28-38. Para um acesso rápido e seguro, cf. http://www.cnbb.org.br/site/component/ docman/ cat_view/134-documentos-cnbb

4 PAULO VI. Evangelii Nuntiandi. Exortação Apostólica. 7. ed. Petrópolis: Loyola, 1987.

5 JOÃO PAULO II. Redemptoris Missio. Carta Encíclica. São Paulo: Paulus, 1997.

6 CNBB. DGAP 1991-1994. (Documentos da CNBB n. 45). São Paulo: Paulinas, 1991, n. 27.

CNBB. DGAP 1991-1994. (Documentos da CNBB n. 45). São Paulo: Paulinas, 1991, n. 75. 
Dimensão missionária ${ }^{8}$ é, assim como as outras cinco Linhas ou Dimensões, apenas um aspecto da Pastoral e não o conteúdo e a razão em si de ser de toda a ação da Igreja que se concretiza na pastoral. ${ }^{9} \mathrm{~A}$ missionariedade, ressaltada como Essência e Razão de ser da Igreja, como nos aponta o Concílio e a Evangelii Nuntiandi, é aprisionada numa linha ou dimensão da pastoral.

A proposta conciliar, assim como dos outros documentos pontifícios somados à realidade religiosa brasileira, exigirá um entendimento mais preciso do lugar da missão-evangelização que melhor ressalte a própria vocação da Igreja e, consequentemente, a sua essencialidade enquanto ação junto ao povo de Deus e à sociedade.

Diante de uma sociedade que se deixa influenciar e contaminar-se pelos múltiplos valores da Modernidade,$^{10}$ que tipo de postura tomar? Como atuar diante desta nova cultura hodierna que se instala e é tão vivamente agressiva aos valores evangélicos e nocivas aos homens? É possível responder aos apelos dos homens e das mulheres de hoje por meio de uma nova evangelização, como o Papa João Paulo II tem insistido tanto?

8 Como se sabe, toda a riqueza dos documentos conciliares foi acolhida e assumida pela Igreja do Brasil, por meio da construção das seis Linhas ou Dimensões da Pastoral expressas pelo PPC. Essas seis Diretrizes mantêm, tanto em sua fundamentação quanto em sua execução, uma profunda e total relação de dependência umbilical para ser mais preciso, aos documentos do Concílio Vaticano II e, de maneira toda especial, com a Constitutio De Ecclesia (LG). Essas seis Linhas ou Dimensões constituem para a vida e o Planejamento Pastoral da Igreja no Brasil a consequência imediata e original do Concílio Vaticano II. Tanto é que prevalecerão até o ano de 1994, iluminando toda a ação pastoral da Igreja no Brasil e, consequentemente, todos os empreendimentos futuros. CF. PPC p. 61-109. Também, GODOY, M.J. A CNBB e o processo de evangelização do Brasil. In: INSTITUTO NACIONAL DE PASTORAL (Org.). Presença Pública da Igreja no Brasil (1952-2002): Jubileu de ouro da CNBB. Op. cit. p. 389-340; BEOZZO, J. O. Igreja no Brasil: Planejamento Pastoral em Questão. In: REB, Petrópolis, v. 42, n. 167, p. 465-472, [setembro] 1982. BEOZZO, J. O. A recepção do Vaticano II na Igreja do Brasil. In: INSTITUTO NACIONAL DE PASTORAL (Org.). Presença Pública da Igreja no Brasil (1952-2002): Jubileu de ouro da CNBB. Op. cit., p. 443-44.

9 Cf. CNBB. DGAP 1991-1994. (Documentos da CNBB, n. 45). São Paulo: Paulinas, 1991, n. 84.

10 Cf. CNBB. DGAP 1991-1994. (Documentos da CNBB n. 45). São Paulo: Paulinas, 1991, n. 152-166. Para um melhor entendimento do que é a Modernidade, cf. DE ÁVILA, F.B. Modernidade. In: Pequena Enciclopédia de Doutrina Social da Igreja. São Paulo: Loyola, 1991, p. 299. 
Para responder a essa questão, é preciso descrever alguns aspectos da eclesiologia inerente às Diretrizes propostas para o quadriênio de 19911994. Fundamentalmente, a Igreja do Brasil é a Igreja do Vaticano II que procurou inserir-se no mundo, dialogar com ele, da valorização do fiel leigo, engajando-o na comunidade (CEBs), inserindo-se, por meio da diversidade das pastorais, em todos os âmbitos sociais. Contudo, é necessário percebermos que a Igreja no Brasil viveu de forma unilateral, "uma inclinação horizontalista, com acentuados apelos sociais, quase exclusivamente ao social. Pouco, ou quase nada, se falava da função salvadora e sacramental da Igreja"."11

A Igreja no Brasil é sem dúvida, um sinal unívoco no que se refere à construção de uma sociedade mais justa e fraterna. Mas, nesta tentativa de construí-la, embrenhou-se em funções eminentemente sociais e libertárias, justas e necessárias segundo o próprio Evangelho, mas que não constituem, nem a totalidade de sua missão e nem a sua essencialidade. A Igreja, por muito tempo, esqueceu que era preciso evangelizar como Paulo VI nos lembra: é "uma proclamação clara que, em Jesus Cristo, Filho de Deus feito homem, morto e ressuscitado, a salvação é oferecida a todos os homens, como dom da graça e da misericórdia do mesmo Deus". ${ }^{12}$ De forma categórica, afirma que "não haverá nunca evangelização verdadeira se o nome, a doutrina, a vida, as promessas, o reino, o mistério de Jesus de Nazaré Filho de Deus não forem anunciados".13 Por último, a define de forma clássica: "Efetivamente, a totalidade da evangelização para além da pregação de uma mensagem consiste em implantar a Igreja, a qual não existe sem esta respiração, que é a vida sacramental a culminar na Eucaristia". ${ }^{14}$

Neste ínterim, aquilo que nós, católicos, não demos tanta importância, como a pregação, a catequese, a sacramentalização, a liturgia, ${ }^{15}$ que fazem o crente transcender-se e, ao mesmo tempo impulsionados por esta transcendência, engajar-se em sua vida concreta, ficamos em discursos e em ações eminentemente imanentes que não proporcionaram ao fiel de transcender-se. Por isso, perdemos na qualidade de cristianismo e,

11 DE MiRAndA, A. A. A Pastoral em face da Modernidade e da Pós-Modernidade. In: Atualização, Belo Horizonte, n. 236, [março/abril] de 1992, p. 176.

12 EN, n. 27-28.

13 EN, n. 22.

14 EN, n. 28.

15 EN, n. 42-43. 
consequentemente, perdemos fiéis ${ }^{16}$ para as outras religiões que estavam preocupadas em responder aos apelos de fé dos fiéis e não se eles têm ou não direitos, mesmo que isto seja relevante, mas não é tudo. Enquanto ficamos preocupados em dar assistência jurídica e reivindicar os direitos dos pobres, que é louvável, por outro lado, esquecemos de dar-lhes também o pão da fé, o direito de expressar a sua religiosidade, de transcender-se. Os protestantes preencheram nossa lacuna.

Quando se fala do protagonismo dos leigos e das CEBs, temos que ressaltar alguns pontos importantes: João Paulo II na Redemptoris Missio, assim como já Paulo VI na Evangelii Nuntiandi, chamava a atenção para a eclesialidade das CEBs. ${ }^{17}$ Historicamente, as CEBs em vez de se tornarem pólos de unidade eclesial, tornaram-se, na maioria delas, salvo exceções, pontos de reivindicações sociais e eclesiais. Os leigos foram cada vez mais conscientizados sobre seus direitos e deveres, mas não sobre o conteúdo da fé; muitos se tornaram insensíveis àqueles que não compartilhavam de suas ideologias. Todos os outros fiéis leigos, que preferiam um outro modo de ser Igreja, eram denominados alienados, enquanto só se podia afirmar ser leigo, aquele que estivesse engajado na luta do e pelo povo. Criou-se, neste ínterim, uma "ditadura da pastoral", na qual só se é engajado aquele que faz parte de uma pastoral. Caso contrário, são todos alienados. Criou-se, uma ruptura entre ser da pastoral e não ser da pastoral. Todos os que não participavam eram considerados cristãos de "segunda categoria".

Num contexto assim, temos um perfil de Igreja horizontalista, pastoralista, engajada na construção do Reino de Deus, segundo as suas forças e não segundo o Evangelho, como afirma o Cardeal Ratzinger. ${ }^{18} \mathrm{~A}$ evangelização, até aqui apresentada pelas Diretrizes, não se tornou o verdadeiro conteúdo da Ação Pastoral. Ademais, conforme o próprio Papa João Paulo II afirmou na Redemptoris Missio, a Pastoral é para uma Igreja que está toda evangelizada e não para uma Igreja que está em estado de evangelização. A Igreja no Brasil deverá passar do adjetivo "Pastoral" para o de "evangelização", visto que a sua missão ainda está longe de se realizar e também neste período distanciada de seu verdadeiro itinerário, como bem

16 CNBB. DGAP 1991-1994. (Documentos da CNBB n. 45). São Paulo: Paulinas, 1991, n. 140.

17 RMi, n. 51.

18 Cf. Revista "30 DIAS", Roma, ano VII, col. 1 e 2, [janeiro] de 1992, p. 38. 
nos lembra Dom Aloísio Lorscheider. ${ }^{19}$ Por isso, quando não se desce ao coração do homem e não se provoca nele a experiência de Deus, não se realiza a evangelização; aplica, quando muito, um "verniz superficial" de informação evangélica. ${ }^{20}$

\subsection{Uma análise do Documento 54}

Essas novas Diretrizes inauguram um novo tempo para a Igreja no Brasil. A partir delas, em consonância com a IV Conferência Episcopal, realizada em Santo Domingo e atendendo aos apelos do Papa para a preparação do Novo Milênio, percebe-se uma nova aurora, uma revolução copernicana na compreensão do lugar da Evangelização na ação da Igreja do Brasil. Há um verdadeiro empenho, primeiramente por parte dos bispos, em aplicar os princípios da nova evangelização. Ela passa de uma mera Dimensão da Pastoral para se tornar à razão de ser e de agir de toda ação pastoral da Igreja.

As novas Diretrizes apresentam a inculturação como exigência aguda e urgente e, por isso, irrenunciável. Ela é o critério geral da ação evangelizadora desenvolvida a partir das quatro exigências: serviço, diálogo, anúncio e testemunho da comunhão. Estas, embora distintas, são complementares e denotam uma tríplice busca da própria Igreja, ou seja, de uma maior compreensão de si mesma e de sua consciência missionária, de uma profunda renovação de suas estruturas e, consequentemente, a busca de uma espiritualidade que possa conjugar essas duas realidades anteriores. ${ }^{21} \mathrm{~A}$ escolha dessas quatro exigências, embora não sejam as únicas possíveis, ${ }^{22}$ obedecem a uma ordem cronológica de inserção numa cultura ou grupo não evangelizado.

19 LORSCHEIDER, A. A IV Conferência Geral do Episcopado Latino-Americano em Santo Domingo - República Dominicana. In: REB, Petrópolis, v. 53, n. 209, [março] de 1993, p. 20.

20 Cf. EN 20.

21 Cf. CNBB. DGAE 1995-1998. (Documentos da CNBB n. 54). São Paulo: Paulinas, 1995, n. 62.

22 CNBB. DGAE 1995-1998. (Documentos da CNBB n. 54). São Paulo: Paulinas, 1995, n. 174. 
A realidade cultural dos povos indígenas, afro-americanos e mestiços ${ }^{23}$ assim como no meio cultural da sociedade hodierna ${ }^{24}$ constituem o lócus desafiador da evangelização inculturada por parte da Igreja. Por sua Ação Evangelizadora, a Igreja no Brasil quer ser uma presença entre todos esses grupos, pois não quer deixar ninguém de fora do raio de sua missionariedade, ${ }^{25}$ sendo para todos, um "sinal da presença divina no mundo". ${ }^{26}$ Desta forma, a comunhão eclesial, deve ser vivida em todos os seus níveis, seja na colegialidade entre os bispos, na colegialidade no Presbitério, na Paróquia, nas Comunidades eclesiais, entre os múltiplos movimentos, etc. Todos devem nutrir-se da Comunhão Trinitária pela oração, pelos sacramentos e pela fraternidade. ${ }^{27}$

Merece ainda destaque a indicação prática que as Diretrizes fazem acerca das Paróquias. Por serem comunidades fundamentalmente eucarísticas, devem configurar-se em comunidades de dimensões humanas, promotoras de relações pessoais fraternas. ${ }^{28}$ Assim, a partir da comunidade, todos, pela "graça do batismo e da crisma" 29 sem distinção, se tornam protagonistas desta ação evangelizadora. O desafio consiste justamente em "despertar cada batizado e cada comunidade eclesial para essa responsabilidade primeira e intransferível". ${ }^{30}$

Consciente de que está diante de novos contextos, num mundo plural tanto do ponto de vista cultural quanto religioso, a Igreja incentiva a todos os fiéis leigos a não temerem "essas novas dificuldades, mas reconhecer nelas novas chances para a obra evangelizadora, renovando o seu ardor, seus métodos e suas expressões". ${ }^{31}$ Juntamente com este dinamismo interior

23 CNBB. DGAE 1995-1998. (Documentos da CNBB n. 54). São Paulo: Paulinas, 1995, n. 179. Cf. Também Op. cit. n. 180-185; DSD, n. 243-251.

24 DSD, n. 252-262.

25 CNBB. DGAE 1995-1998. (Documentos da CNBB n. 54). São Paulo: Paulinas, 1995, n. 230-249.

26 AG, n. 19,22; RMi, n. 49.

27 Cf. CNBB. DGAE 1995-1998. (Documentos da CNBB n. 54). São Paulo: Paulinas, 1995, n. 94.

28 CNBB. DGAE 1995-1998. (Documentos da CNBB n. 54). São Paulo: Paulinas, 1995, n. 279-280.

29 CNBB. DGAE 1995-1998. (Documentos da CNBB n. 54). São Paulo: Paulinas, 1995, n. 105.

30 CNBB. DGAE 1995-1998. (Documentos da CNBB n. 54). São Paulo: Paulinas, 1995, n. 104.

31 CNBB. DGAE 1995-1998. (Documentos da CNBB n. 54). São Paulo: Paulinas, 1995, n. 99. 
de toda a Igreja, as Diretrizes afirmam que a "evangelização nesses novos contextos exige, além da renovação das atuais estruturas pastorais e a criação de novas estruturas que correspondam às exigências de uma nova evangelização, novo ardor, novos métodos, novas expressões e, sobretudo, uma espiritualidade que torne a Igreja cada vez mais missionária". ${ }^{32}$

Sendo assim, a partir dessa exposição, podemos traçar um perfil eclesial que as próprias Diretrizes nos apontam. Esse novo perfil eclesiológico funda-se nesta dupla realidade: renovação das estruturas e numa espiritualidade missionária. No tocante a nossa reflexão, vale a pena recordar que a evangelização sempre foi a temática de nossas Diretrizes. Contudo, quando no Documento 54 , fala-se da necessidade de renovação das estruturas a fim de uma evangelização renovada, ou seja, uma nova evangelização sob os moldes que o Papa João Paulo II nos aponta, nova em seu ardor, em seus métodos e em sua expressão, é importante ressaltar o lugar que a mesma ocupa agora nessas novas Diretrizes.

A partir do Documento 54, a evangelização ocupara a centralidade da vida da Igreja, assim como se pode falar de uma centralidade da Pessoa de Jesus Cristo. Quando falamos da centralidade da Evangelização, temos que, naturalmente, falar da centralidade da pessoa de Jesus, visto que a evangelização é um ato da sua própria Pessoa. É a partir de Jesus Cristo que se pode falar de evangelização e é a partir de sua postura evangelizadora que a Igreja deve forjar a sua. Isto é muito evidente nessas Diretrizes. Desde o enunciado do Objetivo Geral, "Jesus Cristo, ontem, hoje e sempre", as Diretrizes têm em Jesus Cristo o seu ponto de partida, o seu centro e sua meta de convergência. ${ }^{33}$ Desta forma, a centralidade da evangelização é consequência da centralidade transcendente e imanente da Pessoa de Jesus Cristo na construção do agir evangelizador da Igreja.

A importância dada à evangelização inculturada deve-se, necessariamente, a um movimento trinitário, ou seja, da certeza de que o Pai, de antemão por seu Espírito, já soprou e já está presente em todas as pessoas e culturas de todos os tempos, por meio de suas sementes do Verbo. A possibilidade de uma evangelização inculturada parte desse pressuposto,

32 CNBB. DGAE 1995-1998. (Documentos da CNBB n. 54). São Paulo: Paulinas, 1995, n. 101.

33 Cf. CNBB. DGAE 1995-1998. (Documentos da CNBB n. 54). São Paulo: Paulinas, 1995, n. $71 ; 333 ; 340$. 
mas se evidencia como realidade na Encarnação do Filho, que assume a natureza e a cultura de um povo sem deixar de ser Deus, mas vivendo em profundidade a sua realidade humana.

As quatro exigências irrenunciáveis da evangelização inculturada têm, na Pessoa de Jesus Cristo, o seu termo. Embora elas sejam uma continuidade e, ao mesmo tempo, bebem das seis linhas ou dimensões, vale a pena ressaltar que elas apenas evidenciam e corroboram para a concretização da evangelização. Elas evidenciam o agir do próprio Cristo, que serve, dialoga, anuncia e testemunha. Essas quatro exigências, uma vez praticadas pela Igreja, e consequentemente, por todos os batizados, forjarão em cada um e em ambos uma verdadeira identidade não só ontológica, mas, sobretudo testemunhal à luz da vida e da conduta do próprio Mestre Jesus.

A evangelização deve mover toda a estrutura eclesial, desde os ministros ordenados até o último batizado. Todos devem evangelizar, renovando-se interiormente por uma espiritualidade encarnada, cristológica e eclesial. Não haverá novo ardor sem uma verdadeira e profunda experiência com a Pessoa de Jesus Cristo. Embora presente nas outras Diretrizes, o documento 54 é mais enfático quando fala sobre a Mística ou espiritualidade, pois a apresenta como algo indispensável para todos, como algo conatural à vocação cristã e indispensável para o cumprimento da ação evangelizadora.

Neste ínterim, o perfil eclesiológico que se demonstra é este: de uma Igreja centrada em Jesus Cristo, por isso evangelizadora. De uma Igreja que reconhece sua fragilidade e que tem na espiritualidade, centrada no seu Senhor, a força necessária para continuar no mundo a sua missão. Poder-se-ia se perguntar: por que a Igreja no Brasil procurou repensar suas estruturas e seu perfil eclesial? Notoriamente, poderíamos dizer que é por causa de todo o problema da evasão dos católicos nesse período. Esta afirmação evidencia-se com razão, visto que já perdemos muitos fiéis e que todas essas mudanças estruturais querem forjar uma melhor ação evangelizadora a fim de estagnar esse êxodo religioso e o número crescente de pessoas indiferentes a qualquer tipo de religião, vivendo a mais radical forma de intimismo e secularização. 
Contudo, vale a pena lembrar de todo o movimento da Igreja Universal e Continental nessa linha de renovação e a importância do legado do Papa João Paulo II nesse incentivo a uma nova Evangelização. A Igreja do Brasil por meio dessas Diretrizes procurou adequar-se às exigências propostas por todo este movimento iniciado por Paulo VI com a Evangelii Nuntiandi e continuado por João Paulo II. É claro que o problema de fundo para ambas as instâncias é, sem dúvida, o êxodo de fiéis, mas também a preocupação de forjar um rosto eclesial compatível com as novas mudanças estruturais do mundo hodierno e de respondê-los com maior eficácia e eficiência, justificando sua mudança.

Por fim, uma questão: Pastoral ou Evangelização? A evangelização suprimiu a Pastoral? A resposta deve ser objetiva: não. A evangelização não suprimiu ou suprime a Pastoral. A Ação Evangelizadora está ordenada a um grupo específico de cristãos, conforme a RMi apresenta. A Ação Pastoral, para um outro grupo de cristãos. Como, na Igreja, esses dois grupos de pessoas subsistem concomitantemente, tanto a Evangelização é necessária para acordar os católicos adormecidos pelo comodismo, como a Pastoral para alimentar e formar os que já estão na comunidade eclesial, assim como para alimentar e formar os que vão despertando pela ação evangelizadora.

Contudo, a novidade desse novo jeito de ser Igreja consiste nisto: embora os destinatários da ação pastoral já estejam dentro das comunidades, eles precisam constantemente ser evangelizados. A pastoral que os alimenta não pode caminhar sozinha: ela tem que ser regada pela evangelização. Hoje, não se pode falar de pastoral sem prescindir da evangelização. Ela não é um adendo da pastoral, mas a fonte, o alicerce da mesma. Toda pastoral deve ser evangelizadora e toda ação evangelizadora deve levar o crente, o fiel, a um comprometimento pastoral com a comunidade eclesial.

Nesta mesma esteira, as novas Diretrizes, o documento 61, formuladas para o quadriênio de 1999-2002, sob o influxo teológico da Exortação Pós-sinodal Ecclesia in América assim como o Documento sobre o Ecumenismo, Ut unum sint e a Carta Apostólica Fides et Ratio.

Não há, em relação ao documento 54 , mudanças radicais quanto à compreensão teológica acerca da evangelização. Porém, duas novidades 
se apresentam: um novo quadro de dados atualizados acerca da realidade brasileira e no que afirma acerca da exigência do anúncio, acrescenta que a evangelização, para ser autêntica, precisa partir do encontro pessoal com Jesus Cristo. Esse encontro ou essa mediação tem como lócus privilegiado o "estudo e meditação da Sagrada Escritura, na vivência da dimensão celebrativa e nas 'pessoas', especialmente os pobres com os quais Cristo se identifica' A Escritura e a Eucaristia e as pessoas constituem, assim, os lugares, por excelência, do encontro com Cristo na história" que deve ser regado pela conversão". ${ }^{34}$

Nessa afirmação situa o grande avanço dessas Diretrizes. A pessoa humana é, assim como a Escritura, o lugar de encontro com a Pessoa de Jesus Cristo. É a explicitação do valor teológico da pessoa humana expresso pela Revelação, em detrimento do descaso com a mesma, proporcionada pela sociedade secularizada. De forma intraeclesial, resgata e desperta a todos para uma espiritualidade comprometedora com o outro, em que valoriza a relação não somente transcendente, mas também a imanente, não só com Deus numa dimensão vertical, mas, eminentemente, com o próximo, numa dimensão horizontal.

\section{CONCLUSÃO}

O perfil eclesiológico, presente nas Diretrizes, foi, nesse Capítulo, abordado pela via da evangelização. Como o próprio Papa Paulo VI a denomina, ela é um processo rico, dinâmico e inesgotável. Na evolução das Diretrizes, ela foi ganhando, em sintonia com a evolução teológica, seja Pontifícia ou das Conferências Episcopais, realces que, por via de regra, foram denotando à Igreja um perfil único, concretizado na e pela vida pastoral.

Sendo assim, até as Diretrizes Gerais da Ação Pastoral - doc. 45 -, a evangelização era abordada como que uma realidade dentre muitas outras, fazendo parte da linha ou dimensão 2, ou seja, a ação missionária. De acordo com os eventos Teológicos, como o Sínodo sobre a justiça no

34 CNBB. DGAE 1999-2002. (Documentos da CNBB n. 61). São Paulo: Paulinas, 1999, n. 222-223. 
mundo, as Conferências de Medellín, de Puebla, das Encíclicas papais, seja de Paulo VI com a Populorum Progressio e a Evangelii Nuntiandi, seja com João Paulo II com a Redemptoris Missio, Carta Apostólica Tertio Millennio Advenient e Carta Apostólica Novo Millennio Ineunte, a evangelização aqui ia ganhando novos destaques e complementações.

A partir da Encíclica Populorum Progressio e de Medellín, a evangelização foi entendida como evangelização libertadora; com o Sínodo sobre a Justiça no Mundo, como evangelização integral; mas foi a partir da Evangelii Nuntiandi que ela foi acolhida e entendida como o conjunto de atividades da missão da Igreja. Com a Conferência de Puebla, realçou-se o seu conteúdo, ou seja, ela deve estar alicerçada sobre a tríplice verdade, sobre Jesus Cristo, a Igreja e o Homem; mas, é a partir da Redemptoris Missio que foi possível distinguir algo fundamental, ou seja, a distinção quanto aos destinatários da evangelização e da pastoral. Daqui em diante, pastoral-evangelização, formam duas realidades, não separadas, mas ordenadas ontologicamente.

Com a Conferência de Santo Domingo, pediu-se a renovação da evangelização quanto ao seu ardor, aos seus métodos e expressões. Naturalmente, a Igreja do Brasil, com as Diretrizes da Ação Evangelizadora doc. 54 - mudou o seu enfoque: acolheu essas orientações e mudou sua estrutura para melhor responder à sua missão evangelizadora. Em vez de situá-la dentre de uma das seis linhas ou dimensões da pastoral, agora a evangelização é entendida e colocada como o centro, da mesma forma que Cristo é o centro de Tudo, haja vista que Evangelizar é tornar conhecida a Pessoa, a Doutrina, a salvação de Jesus. Em analogia com o mistério da Encarnação, a evangelização deve ser inculturada, prescindindo de quatro exigências irrenunciáveis, a saber, o serviço, o diálogo, o anúncio e o testemunho de comunhão eclesial.

$\mathrm{Na}$ compreensão de continuidade, vemos que o perfil eclesiológico presente no documento 45 , mantém a mesma ideia do documento 54 , ou seja, de uma Igreja evangelizadora. Contudo, o modo de abordá-la é totalmente descontínuo, ou seja, lá era apenas uma parte de uma dimensão, aqui é a centralidade de toda a vida da Igreja. Evangelização e pastoral não se tornaram realidades dicotômicas. Porém, a partir do documento 54 , 
entende-se que toda pastoral deve ser evangelizadora e que a evangelização deve nortear toda ação pastoral.

Notavelmente, conclui-se que a Igreja no Brasil não pode ser somente profética: ela tem que ser Evangelizadora e é por meio da evangelização que a Igreja se torna profética. É por meio da Evangelização que ela pode se tornar um sinal escatológico para e em toda realidade secular. Progressivamente, a Igreja no Brasil deve trilhar com maior profundidade os caminhos da evangelização, a fim de melhor efetuar sua presença entre os mais pobres sem se esquecer de que é Mãe e que tem o dever de também falar a todos os demais. Os homens da Igreja, que trilham os caminhos do novo milênio, devem, na prática e na tomada de consciência, ser semelhantes àqueles que iniciaram a caminhada dessa mesma Igreja, numa perspectiva totalmente evangelizadora.

O esforço grandioso realizado até aqui, permitirá à Igreja do Brasil, uma melhor compreensão e adequação aos futuros eventos que se realizarão nos anos seguintes, como a Conferencia de Aparecida, cujo conteúdo e propostas não são tão estranhos ou contrários àquilo que na realidade concreta se estava vivendo. Esta evolução eclesiológica iniciada não se terminara, pois a evangelização é sempre uma realidade "rica, complexa e dinâmica" 35 como nos lembra Paulo VI. O que se espera é uma Igreja capaz de ser próxima para todos e capaz de ser no mundo um sinal luminoso da presença de Cristo.

\section{BIBLIOGRAFIA}

AZEVEDO, M. de C. Comunidades Eclesiais de Base. São Paulo: Loyola, 1986. BEOZZO, J. O. A Igreja do Brasil: De João XXIIII a João Paulo II - de Medellín a Santo Domingo. Petrópolis: Vozes, 1994.

BEOZZO, J. O. Igreja no Brasil: Planejamento Pastoral em Questão. In: REB, Petrópolis, v. 42, n. 167, [setembro] de 1982.

CODINA, V. Para compreender a Eclesiologia a partir da América Latina. São Paulo: Paulinas, 1993.

35 Cf. EN, n. 17. 
CONFERÊNCIA NACIONAL DOS BISPOS DO BRASIL. Diretrizes Gerais da Ação Pastoral da lgreja no Brasil 1991 - 1994. (Documentos da CNBB n. 45). São Paulo: Paulinas, 1991.

CONFERÊNCIA NACIONAL DOS BISPOS DO BRASIL. Diretrizes Gerais da Ação Pastoral da lgreja no Brasil 1995 - 1998. (Documentos da CNBB n. 54). São Paulo: São Paulo, Paulinas, 1995.

CONFERÊNCIA NACIONAL DOS BISPOS DO BRASIL. Diretrizes Gerais da Ação Pastoral da lgreja no Brasil 1999 - 2002. (Documentos da CNBB n. 61). São Paulo: São Paulo, Paulinas, 1999.

CONSELHO EPISCOPAL LATINO AMERICANO. Conclusões de Medellín, $4^{a}$ ed., São Paulo: Paulinas, 1979.

CONSELHO EPISCOPAL LATINO AMERICANO. Evangelização no presente e no futuro da América Latina: Conclusões da Conferência de Puebla: Texto oficial. 8. ed. São Paulo: Paulinas, 1987.

CONSELHO EPISCOPAL LATINO AMERICANO. Nova Evangelização, Promoção Humana, Cultura Cristã: Conclusões da Conferência de Santo Domingo: Texto oficial: Petrópolis: Vozes, 1992.

COSTA, Lourenço (org.). Documentos do Concílio Ecumênico Vaticano II (1962 - 1965). São Paulo: Paulus, 1997.

DE ÁVILA, F. B. Modernidade. In: Pequena enciclopédia de Doutrina Social da Igreja. São Paulo: Loyola, 1991.

DE MIRANDA, A. A. A Pastoral em face da Modernidade e da Pós-Modernidade. In: Atualização, Belo Horizonte, n. 236, [março/abril] de 1992.

DUSSEL, E. De Medellín a Puebla. São Paulo: Paulinas. s/d.

DUSSEL, E. História da Igreja Latino-Americana (1930-1985). São Paulo: Paulinas, 1989.

FREITAS, M. C. de. Uma opção renovadora: A Igreja no Brasil e o planejamento pastoral. São Paulo: Loyola. s/d.

INSTITUTO NACIONAL DE PASTORAL (Org.). Presença Pública da Igreja no Brasil (1952-2002): Jubileu de ouro da CNBB.

JOÃO PAULO II. Carta Apostólica Tertio Millennio Adveniente. São Paulo: Loyola, 1994.

JOÃo PAULO II. Novo Millennio Ineunte. Carta Apostólica. São Paulo: Loyola, 2001.

JOÃO PAULO II. Redemptoris Missio. Carta Encíclica. São Paulo: Paulus, 1997. LIBANIO, J. B. Concílio Vaticano II: em busca de uma primeira compreensão. São Paulo: Loyola, 2005. Col. "Theologka". 
LIBANIO, J. B. Igreja Contemporânea: encontro com a modernidade. São Paulo: Loyola, 2000. Col. CES.

LORSCHEIDER, A. A IV Conferência Geral do Episcopado Latino-Americano em Santo Domingo - República Dominicana. In: REB, Petrópolis, v. 53, n. 209, [março] de 1993.

MANZATTO. A. As Primeiras Conferencias do CELAM. In: Vida Pastoral, São Paulo, ano XLVII, n. 249, [julho/agosto] de 2006.

PAULO VI. Evangelii Nuntiandi. Exortação Apostólica. 7. ed. Petrópolis: Loyola, 1987.

QUEIROGA, G. F. CNBB: comunhão e corresponsabilidade. São Paulo: Paulinas, 1977

Revista "30 DIAS", Roma, ano VII, col. 1 e 2, [janeiro] de 1992.

SUESS, P. (org.). Culturas e Evangelização: a unidade da razão evangélica na multiplicidade de suas vozes: Pressupostos, desafios e compromissos. São Paulo: Loyola, 1991.

52 Revista de Cultura TeOlógica - v. 20 - N. 80 - OUT/DEZ 2012 